\title{
Evaluation of surface roughness and hardness of different glass ionomer cements
}

\author{
Oya Bala' \\ Hacer Deniz Arisu' \\ Ihsan Yikilgan² \\ Seda Arslan ${ }^{1}$ \\ Abdulkadir Gullu ${ }^{3}$
}

\section{ABSTRACT}

Objectives: The aim of this study was to evaluate surface roughness and hardness of a nanofiller GIC, a resin-modified GIC, three conventional GICs, and a silver-reinforced GIC.

Methods: For each material, 11 specimens were prepared and then stored in distilled water at $37^{\circ} \mathrm{C}$ for $24 \mathrm{~h}$. The surface roughness of 5 specimens was measured using a surface profilometer before polishing and after polishing with coarse, medium, fine, superfine aluminum oxide abrasive Sof-Lex discs respectively. The hardness of the upper surfaces of the remaining 6 specimens was measured with a Vickers microhardness measuring instrument.

Results: All tested GICs showed lower surface roughness values after the polishing procedure. Surface finish of nanofiller GIC was smoother than the other tested GICs after polishing. This was followed by resin-modified GIC, Fuji II LC; then silver-reinforced GIC, Argion Molar, conventional GICs, Aqua Ionofil Plus, Fuji IX, and Ionofil Molar, respectively. The result of the hardness test indicated that the microhardness value of silver-reinforced GIC was greater than that of the other GICs. When the hardness values of all tested GICs were compared, the differences between materials lexcept Aqua lonofil Plus with lonofil Molar and Ketac N100 with Fuji II LC (P>.05)) were found statistically significant $(P<.05)$.

Conclusions: According to the results of this study, it can be concluded that the differences in the composition of GICs may affect their surface roughness and hardness. (Eur J Dent 2012;6:79-86)

Key words: Glass ionomer cement; surface roughness; hardness.

1 University of Gazi, Faculty of Dentistry, Department of Operative \& Restorative Dentistry, Ankara, TURKIYE.

2 Abant Izzet Baysal University, Faculty of Dentistry, Department of Restorative Dentistry and Endodontics, Bolu, TURKIYE.

${ }^{3}$ University of Gazi, Faculty of Technical Education, Department of Engine Education, Ankara, TURKIYE.

- Corresponding author: Dr. Oya BALA,

Gazi Üniversitesi, Diș Hekimliği Fakültesi, Diș Hastalıkları ve Tedavisi Anabilim Dalı, Emek (06510), Ankara, TURKIYE.

E-mail: oyabaladgazi.edu.tr

\section{INTRODUCTION}

Conventional glass ionomer cements (GICs) that undergo setting through an acid-base reaction between an ion-leachable glass and aqueous polyacid. ${ }^{1}$ They have been widely used in restorative dentistry because of their advantageous properties including biocompatibility, ${ }^{2}$ adhesion to tooth structure, ${ }^{3}$ and fluoride release. ${ }^{4}$ However, these materials have some clinical limitations such as 
prolonged setting reaction time, moisture sensitivity during initial setting, dehydration, and rough surface texture, which can hamper mechanical resistance. ${ }^{5}$ To overcome these shortcomings, resin-modified glass ionomer cements (RMGICs) were developed. In addition to the conventional GIC formulation, these materials contain monomers and photo initiators. ${ }^{6}$ Cement setting starts when two components are mixed together due to an acid-base reaction. Light exposure causes the creation of cross bonds between polymeric chains and polymerization of methacrylate. ${ }^{7}$ Thus, the reaction may be finished immediately after light exposure, so that operators can have a longer working time. ${ }^{8}$

Metal-reinforced glass ionomer cements were introduced to the dental market in 1977. The addition of silver-amalgam alloy powder to conventional materials increase the physical strength of the cement and provide radiopacity. ${ }^{9}$ They can be used to restore Class II cavities by tunnel preparation, deciduous teeth (especially Class I), core build-ups and retrograde root filling.

Recently, several faster-setting, high-viscosity conventional GICs, originally developed for use with the atraumatic restorative treatment ${ }^{11}$ have become available. These are called "viscous" or "condensable" GICs by some authors. ${ }^{10}$ These materials set faster and having a higher viscosity because of presence of finer glass particles, anhydrous polyacrylic acids of high molecular weight, and a high powder-to-liquid mixing ratio. ${ }^{10,11}$ The setting reaction is the same as the acid-base reaction of a typical conventional GIC.

One of the latest developments in GICs is a nanofiller GIC which contains nano-sised powder particles and fluorapatite. The benefit gained from RMGICs and bonded nanofiller technology is that they can provide the glass ionomer with improved polish and esthetic properties. Although some studies ${ }^{5,6,12}$ exist concerning the mechanical properties of conventional GICs and resin-modified GICs, there is no sufficient information about novel nanofiller GICs.

GICs have been used for different purposes in dentistry in restoring incipient carious lesions especially in primary teeth. In the dental market, there are various GICs possessing distinctive properties; and recent ones are added every day; it is crucial to have knowledge about the physical and mechanical properties of different brands and new products when choosing GICs as restorative material. Therefore, the aim of this study was to evaluate surface roughness and hardness of six different GICs and determine whether there is any correlation between GICs' surface roughness and hardness.

\section{MATERIALS AND METHODS}

Sample Preparation

A nanofiller GIC (Ketac N100), a resin-modified GIC (Fuji II LC), 3 conventional GICs (Fuji IX, lonofil Molar, Aqua Ionofil Plus), and a silver-reinforced GIC (Argion Molar) were used in this study. The chemical compositions of these materials are listed in Table 1.

A sectional Teflon mold $(8 \mathrm{~mm}$ diameter $\times 2 \mathrm{~mm}$ deep) was used to prepare the sample. The mold was first mounted on top of a glass plate and a Mylar strip. The materials were mixed or handled according to their manufacturers' instructions and inserted into the molds slightly excessively. The Mylar strip was positioned on the mold, and a second glass plate was then placed on top of the filled mold. A slight pressure was applied, and the bulk of the extruded excess cement was removed. For the light-curing GICs (Ketac N100 and Fuji II LC), specimens were cured with 20 s exposures by a halogen light-curing unit (Hilux, Benlioğlu, Ankara, Turkey). The light intensity was measured with a radiometer (Hilux, Benlioğlu, Ankara, Turkeyl before starting the experiment. The mean output was $900 \mathrm{~mW} / \mathrm{cm}^{2}$. Immediately after light polymerization, the Mylar strips were discarded. The prepared samples were then stored in a distilled water at $37^{\circ} \mathrm{C}$ for $24 \mathrm{~h}$. Eleven samples were prepared from each material.

\section{Surface Roughness}

For the surface roughness test, 5 samples from each material were used and kept in the mold throughout the experiment. The surface roughness of each specimen was measured in 5 different positions initially before polishing using a surface profilometer (Surftest 211, Mitutoyo, Tokyo, Japan). The cut-off value for surface roughness was $0.8 \mathrm{~mm}$, and the traversing distance of the stylus was $4.0 \mathrm{~mm}$. The radius of the tracing diamond tip was $5 \mu \mathrm{m}$, the measuring force and speed were $4 \mathrm{mN}(0.4 \mathrm{gf})$ and $0.5 \mathrm{~m} \mathrm{~s}^{-1}$, respec- 
Table 1. List of materials investigated in this study.

\begin{tabular}{|c|c|c|c|}
\hline Materials & Type & Average particle size $(\mathrm{mm})$ & Composition \\
\hline $\begin{array}{l}\text { Ketac N100 3M-ES } \\
\text { PE, St. Paul, USA, \#20080805 }\end{array}$ & $\begin{array}{l}\text { Light-curing } \\
\text { nano-ionomer restorative }\end{array}$ & $\begin{array}{c}\text { Nanofillers }-5-25 \mathrm{~nm} \text {, } \\
\text { Nanoclusters - } 1.0-1.6 \mathrm{~mm}\end{array}$ & $\begin{array}{c}\text { Deionized water, HEMA, FAS, nonomers and } \\
\text { nanoclusters, methacrylate modified } \\
\text { polyalkenoic acid }\end{array}$ \\
\hline $\begin{array}{l}\text { Fuji II LC, GC Corporation, } \\
\text { Tokyo, Japan, \#9000180605261 }\end{array}$ & $\begin{array}{l}\text { Light-curing } \\
\text { glass-ionomer restorative }\end{array}$ & $5.9 \mu \mathrm{m}$ & $\begin{array}{l}\text { Distilled water, polyacrylic acid, HEMA, } \\
\text { urethanedimethacrylate, silicone dioxide, } \\
\text { aluminosilicate glass, urethanedimethacrylate }\end{array}$ \\
\hline $\begin{array}{l}\text { Fuji IX, GC Corporation, Tokyo, } \\
\text { Japan, \#0810252 }\end{array}$ & $\begin{array}{l}\text { Conventional } \\
\text { glass-ionomer cement } \\
\text { restorative }\end{array}$ & $10.0 \mu \mathrm{m}$ & $\begin{array}{l}\text { Water, carboxylic acid, polyacrilic acid, polybasic } \\
\text { aluminofluorosilicate glass }\end{array}$ \\
\hline $\begin{array}{l}\text { Ionofil Molar, Voco, Cuxhaven, } \\
\text { Germany, \#020225 }\end{array}$ & $\begin{array}{l}\text { Conventional } \\
\text { glass-ionomer cement } \\
\text { restorative }\end{array}$ & $5 \mu \mathrm{m}$ & $\begin{array}{l}\text { Water, pure polyacrylic acid, tartaric acid, } \\
\text { aluminofluorosilicate glass and pigments }\end{array}$ \\
\hline $\begin{array}{l}\text { Aqua lonofil Plus, Voco, } \\
\text { Cuxhaven, Germany, \#690313 }\end{array}$ & $\begin{array}{l}\text { Water-mixable } \\
\text { conventional } \\
\text { glass-ionomer cement } \\
\text { restorative }\end{array}$ & $8 \mu \mathrm{m}$ & $\begin{array}{l}\text { Water, pure polyacrylic acid, tartaric acid, } \\
\text { aluminofluorosilicate glass and pigments }\end{array}$ \\
\hline $\begin{array}{l}\text { Argion Molar, Voco, Cuxhaven, } \\
\text { Germany, \#410801 }\end{array}$ & $\begin{array}{l}\text { Water-mixable silver glass } \\
\text { ionomer restorative }\end{array}$ & $8 \mu \mathrm{m}$ & $\begin{array}{l}\text { Silver particles, polyacrilic acid, wine acid and } \\
\text { earthalkali aluminofluorosilicate glass }\end{array}$ \\
\hline
\end{tabular}

tively. The average roughness value $(\mathrm{Ra}, \mu \mathrm{m})$ of an individual disc was taken as the mean of the Ra (average of peaks and valleys of a surface) values measured in 5 different positions.

Each sample was then polished sequentially with coarse, medium, fine, and superfine aluminum oxide abrasive discs (Sof-Lex, 3M, St Paul, MN, USA). The discs were mounted on a slow-speed hand piece (CA111, Bien Air Dental, Bienne, Switzerland) rotating at approximately $20000 \mathrm{rpm}$. The process was carried out by a single operator as the manufacturer's directions with light hand pressure in a circular pattern for $20 \mathrm{~s}$, per each Sof-Lex disc. A new disc was used for each specimen. After the polishing procedure was completed, surface roughness was measured in 5 different positions parallel to the first measurements using the surface profilometer.

After polishing, 1 sample of the tested materials was prepared for scanning electron microscopy (ISM-840A, Jeol, Tokyo, Japan). Samples were sputter coated with gold to a thickness of approximate-

Table 2. Effect of polishing on surface roughness (Ra, $\mu \mathrm{m})$ of GICs $(n=5)$.

\begin{tabular}{lcc}
\hline Materials & $\begin{array}{c}\text { Before Polishing* } \\
\text { Mean Ra (sd) }\end{array}$ & $\begin{array}{c}\text { After Polishing* } \\
\text { Mean Ra (sd) }\end{array}$ \\
\hline Ketac N100 & $0.44(0.06)^{\mathrm{a}}$ & $0.48(0.12)^{\mathrm{a}}$ \\
\hline Fuji II & $0.56(0.09)^{\mathrm{ab}}$ & $0.71(0.18)^{\mathrm{ab}}$ \\
Fuji IX & $0.74(0.13)^{\mathrm{b}}$ & $0.89(0.12)^{\mathrm{bc}}$ \\
lonofil Molar & $0.78(0.12)^{\mathrm{b}}$ & $0.88(0.80)^{\mathrm{c}}$ \\
\hline Aqua lonofil Plus & $0.71(0.04)^{\mathrm{b}}$ & $0.98(0.25)^{\mathrm{bc}}$ \\
\hline Argion Molar & $0.64(0.12)^{\mathrm{ab}}$ & $0.75(0.11)^{\mathrm{abc}}$ \\
\hline
\end{tabular}

*Vertical values with same superscript letter are not significantly different (P>.05]. samples were used. After being polished with aluminum oxide abrasive discs, the hardness of the upper surfaces was measured using the Vickers microhardness measuring instrument (HMV Microhardness Tester, Shimadzu, Japan). A 200-gf load was applied through the indenter with a dwell time of $15 \mathrm{~s}$. Five readings were taken for each specimen, and the mean Vickers' Hardness value was recorded.

\section{Statistical Analysis}

One-way analysis of variance (ANOVA) with the post-hoc Tukey-Kramer HSD multiple-range test was used to determine significant differences among the materials in each test a significance level of $a=.05$. Paired samples t-test was used to compare the before and after polishing measurements $(a=.05)$. Linear regression analyses and correlation coefficients were calculated between surface roughness and hardness. Statistical analyses were conducted by using SPSS 15.0 program (SPSS Inc., Chicago, USA ).

\section{RESULTS}

\section{Surface Roughness}

Mean and standard deviations of surface roughness ( $R a$ ) are shown in Table 2. Ra values are graphically depicted in Figure 1.

All tested GICs showed lower surface roughness values after the polishing procedure. When the materials were compared before and after polishing surface roughness values, resin-modified GIC (Fuji II LC), conventional GIC (Fuji IX), and silver- 


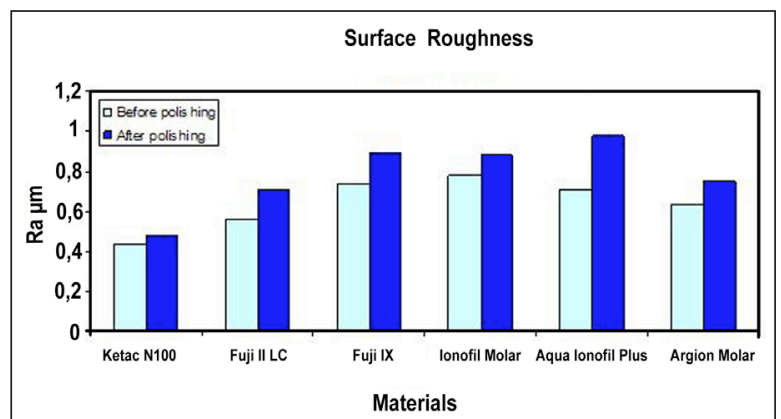

Figure 1. Means of surface roughness (Ra $\mu \mathrm{m}$ ) for tested materials.
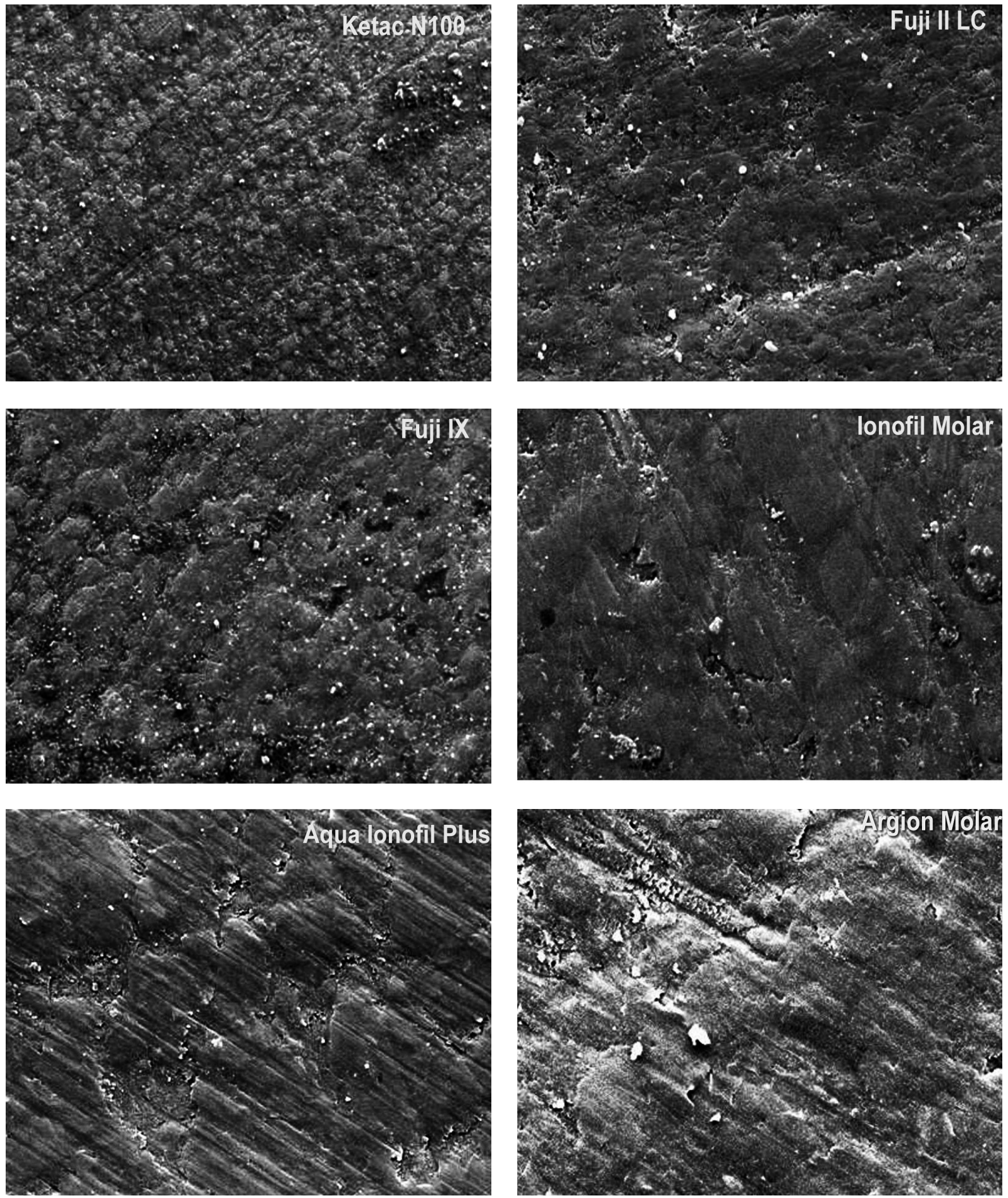

Figure 2. SEM photographs of tested GICs at x2000 after polishing

reinforced GIC (Argion Molar) showed statistically significant differences $(P<.05)$. There were no statistically significant difference between before and after polishing surface roughness values in nanofiller GIC (Ketac N100) and conventional GICs (lonofil Molar, Aqua lonofil Plus) (P>.05).

The smoothest surface before the polishing procedure was observed in nanofiller GIC (Ketac N100).
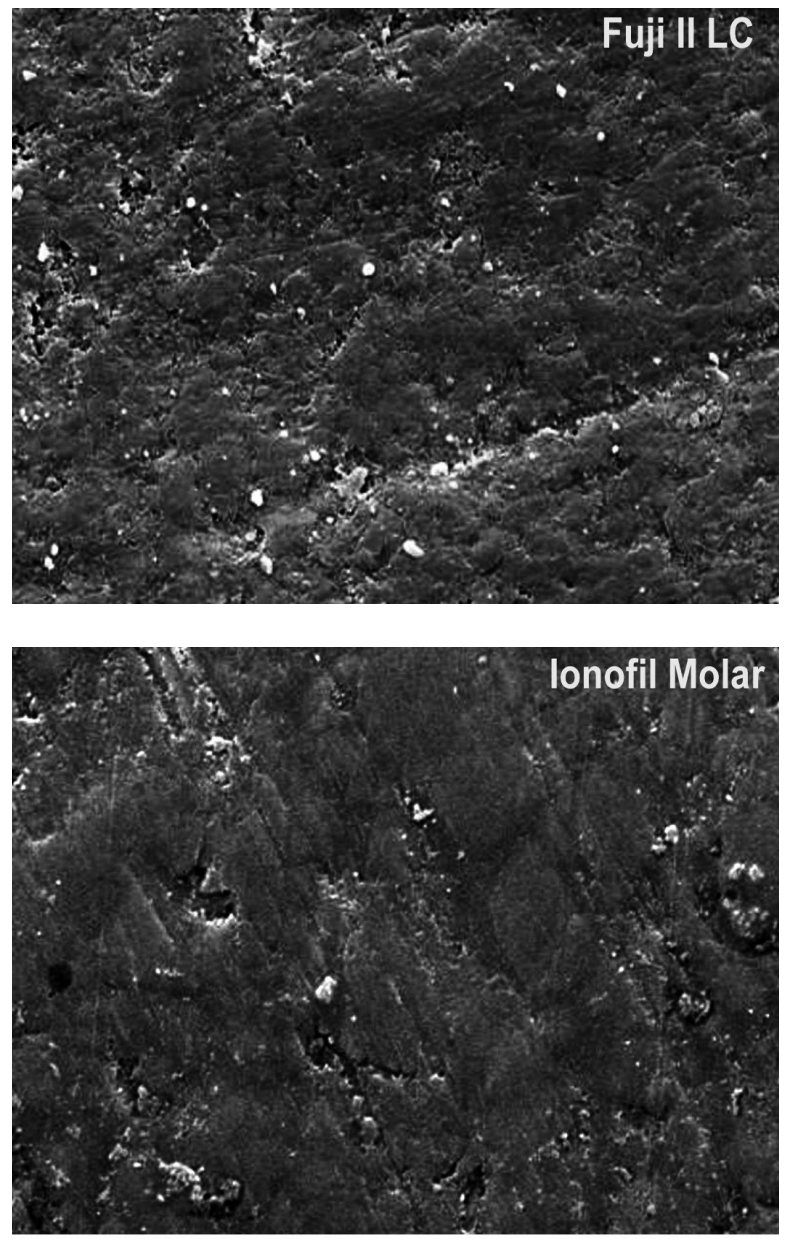
This was followed by resin-modified GIC, Fuji II LC; then silver-reinforced GIC, Argion Molar, conventional GICs, Aqua Ionofil Plus, Fuji IX, and Ionofil Molar, respectively. Before the polishing procedure, there were no significant differences among the surface roughness values of all materials $(P<.05)$ except between the nanofiller GIC Ketac N100 (P>.05).

After the finishing procedure, it was observed that the surface roughness was the lowest in nanofiller GIC Ketac N100 and highest in conventional GIC and Aqua Ionofil Plus.

The SEM photomicrographs obtained in this study showed that, regardless of the commercial brand, all the conventional GICs presented voids and cracks on their surfaces (Figure 2).

\section{Microhardness}

Mean and standard deviations of surface hardness values are shown in Table 3. The result of the microhardness test indicated that the microhardness value of silver-reinforced GIC Argion Molar was greater than that of the other GICs. Among the all conventional GICs examined, Fuji IX showed the lowest hardness value. When the hardness values of all tested GICs were compared, the differences between materials (except Aqua Ionofil Plus with Ionofil Molar and Ketac N100 with Fuji II LC (P>.05)) were found statistically significant $(P<.05)$.

Linear regression showed that there is no correlation between surface roughness and hardness of tested GICs ( $t=1.141, P=.264$ )

\section{DISCUSSION}

In the present study, the values of average Ra for all tested GICs before and after polishing were within range of $0.44-0.78 \mu \mathrm{m}$ and $0.48-0.98 \mu \mathrm{m}$ range, respectively. This suggests that the composition of the materials may be responsible for these differences. Bollen et $\mathrm{al}^{13}$ examined the relation between the Ra values of titanium implants and bacterial adhesion and reported that the critical surface roughness $(\mathrm{R} a$ ) for bacterial colonization is 0.2 $\mu \mathrm{m}$. Surface roughness higher than $0.2 \mu \mathrm{m}$ is likely to increase significantly bacterial adhesion, dental plaque maturation, and acidity, which act on material surfaces, thus increasing caries risk. In this study, all GICs presented surface roughness below this value both before and after polishing. However, other studies reported no appreciable difference in plaque accumulation between surfaces polished by different methods that resulted in Ra values within $0.7-1.4 \mu \mathrm{m}$ range. ${ }^{14,15}$

Similar to the results of the current study several authors have shown the smoothest surfaces of GICs are obtained with the Mylar strip. ${ }^{16,17}$ However, the correct anatomic contour of the restoration is rarely achieved by using only a Mylar strip. ${ }^{18}$

For finishing and polishing procedures, several systems can be used such as fluted carbide burs, diamond burs, white abrasive stones, and aluminum-oxide discs. However, the literature showed that aluminum-oxide discs allow better surface characteristics for GICs. ${ }^{16,19}$ Therefore, in the present study, aluminum oxide discs were chosen for the polishing procedure of GICs.

Finishing and polishing of esthetic restorative materials always pose a difficulty because particles and matrix differ in hardness and thus cannot be abraded uniformly. ${ }^{20,21}$ For a finishing system to be effective, the cutting particles must be harder than the filler materials. Otherwise, the polishing agent will only remove the matrix and leave the particles protruding from the surface. ${ }^{22}$

In the present study, nanofiller GIC Ketac N100 showed smoother surfaces than the other tested GICs both before and after polishing $(P<.05)$. Some in vitro studies have also demonstrated that the addition of nanofillers provides enhanced surface wear and polish relative to some other commercially available dental materials. ${ }^{23}$

The silver-reinforced GIC and Argion Molar had average roughness values ( $\mathrm{Ra}$ ) of $0.64 \mu \mathrm{m}$ and 0.75 $\mu \mathrm{m}$, respectively. These values were near to the average roughness value (Ra) of resin-modified GIC, Fuji II LC, nanofiller GIC, and Ketac N100. The silver reinforcing can improve the wear resistance as well as the brittleness of GICs. However, the reinforcing effects of metal additives to glass ionomers have

Table 3. Vickers hardness values of GICs $(n=6)$.

\begin{tabular}{ll}
\hline Materials & Mean (sd)* \\
\hline Ketac N100 & $37.79(4.18)^{\text {a }}$ \\
\hline Fuji II & $42.28(1.82)^{\mathrm{a}}$ \\
\hline Fuji IX & $26.37(4.40)^{\mathrm{b}}$ \\
\hline lonofil Molar & $74.27(6.67)^{\mathrm{c}}$ \\
\hline Aqua lonofil Plus & $71.18(6.63)^{\mathrm{c}}$ \\
\hline Argion Molar & $85.15(4.58)^{\mathrm{d}}$ \\
\hline
\end{tabular}

*Vertical values with same superscript letter are not significantly different ( $p>05)$. 
been the subject of many controversies. Although some investigators found significant differences between the strengths of conventional and reinforced materials, ${ }^{27,28}$, others found no difference. ${ }^{24-26}$ The absence of interfacial bonding, which is critical for efficient transfer of stress from the matrix to the reinforcement, may explain why metal-reinforced materials have not proved to be stronger or more durable than their metal-free counterparts. ${ }^{29}$

Metal-reinforced GICs have been superseded by highly viscous conventional GICs like Fuji IX. Highly viscous conventional GICs' has enhanced mechanical properties by their improved chemistry and also they are tooth colored. Preliminary studies have shown that highly viscous GICs have either comparable or superior mechanical properties and wear resistance to metal-reinforced cements. ${ }^{30}$

Particle size has been shown to play an important role in how well a material polishes. Some studies have been recorded the highest values of surface roughness for the materials with larger particle sizes. ${ }^{12,22}$ On the other hand, for the GICs, Gladys et al ${ }^{12}$ noted that a material with small particle sizes (Photac Fil, mean particle size $5.56 \mu \mathrm{m}$ ) was 10 times rougher after being polished than lonosit Fil (mean particle size $9.3 \mu \mathrm{m}$ ), which has larger particles. Others have shown that smaller glass particles are abraded rather than larger particles. ${ }^{31}$ In the present study, after polishing, the lonofil Molar material with small particle sizes (mean particle size $5.0 \mu \mathrm{m}$ ) was rougher than the others (Fuji II LC, $5.9 \mu \mathrm{m}$ ) and Argion Molar (8 $\mu \mathrm{m}$ ) with the larger particle sizes (Table 1). Adversely, lonofil Molar with a small particle size showed smoother surfaces than the Fuji IX with an average particle size of $10 \mu \mathrm{m}$ and Aqua Ionofil Plus with an average particle size of $8.0 \mu \mathrm{m}$. Therefore, the materials with small particles do not invariably show a smoother surface. Hence, other parameters such as differences in shape, distribution, and number of particles; interfacial bonding between particles; and interfacial bonding between particles and matrix may contribute to a material's surface finish. ${ }^{12}$

Also, the storage media of GIC specimens can affect their surface roughness. In the present study, the prepared GIC specimens were stored in distilled water at $37^{\circ} \mathrm{C}$ for $24 \mathrm{~h}$ to mimic clinic conditions. The chemical dissolution process can produce an increase in surface roughness. ${ }^{32}$ However; one study evaluated the effects of storage media upon the surface micromorphology of resin-based materials and revealed no statistically significant difference in surface roughness between specimens exposed to distilled deionized water or artificial saliva. ${ }^{33}$

GICs' liquid component might influence their surface roughness as well. The conventional GIC is usually supplied as a powder and polyacid liquid. When the polyacid is present in solution, an increase in the viscosity of the liquid occurs, making the cement paste progressively more difficult to manipulate. Hence, nowadays manufacturers are using the polyacrylic acid in solid form for blending with glass ionomer powder rather than using polyacid liquid. Aqua lonofil Molar used in this study is a water-mixable conventional GIC. Water-mixed GICs have a low viscosity in the early mixing stages plus improved shelf life because there is no possibility of gelation occurring in its liquid. ${ }^{34}$

GICs' surface hardness may be affected by the polishing process because the later involves polishing of the glass particles and the abrasion of the matrix or depleted glass layer. In the present study, the highest hardness values were observed in conventional GICs, except in the highly viscous conventional GIC, Fuji IX. There are some studies supporting that surface hardness of conventional GICs is higher than the surface hardness of resin-modified GICs. ${ }^{31,35}$ It has been claimed that the inclusion of resins in the resin-modified GIC does not improve the surface microhardness of these materials. ${ }^{36}$ The findings of the present study suggest that insertion of resin particles as in Fuji II LC or nanoparticles as in nanofiller GIC Ketac N100 did not enhance the surface hardness of these materials.

Also, in the present study, there was no linear regression found between surface roughness and hardness, so it can be concluded that the surface roughness of GICs might be affected by other factors like the differences in the composition of tested GICs rather than their surface hardnesses.

The SEM photomicrographs obtained in this study showed that all conventional GICs presented voids and cracks on their surface. Despite the differences in mean values of the roughness, SEM examination revealed a similar morphological surface pattern for each material. The cracks could be produced during specimen processing for SEM 
analysis, while the voids were probably included during mixing of GIC powder and liquid.

\section{CONCLUSIONS}

Within the limits defined in the present study, the following conclusions can be drawn:

1. Different surface roughness and hardness values were obtained from GICs, and this finding may be due to their different compositions.

2. The smoothest surfaces for all GICs were obtained when cured in contact with a Mylar strip.

3. While the smoothest surfaces were obtained for nanofiller GIC Ketac N100, the roughest surfaces were obtained especially from conventional GICs.

4. The silver reinforced GIC had the highest microhardness value.

5. There was no correlation between surface roughness and hardness of GICs.

\section{REFERENCES}

1. McCabe JF. Resin-modified glass-ionomers. Biomater 1998; 19:521-527.

2. Modena KC, Casas-Apayco LC, Atta MT, Costa CA, Hebling J, Sipert CR, Navarro MF Santos CF. Cytotoxicity and biocompatibility of direct and indirect pulp capping materials. J Appl Oral Sci 2009;17:544-554.

3. Glasspoole EA, Erickson RL, Davidson CL. Effect of surface treatments on the bond strength of glass ionomers to enamel. Dent Mater 2002;18:454-462.

4. Bala O, Uçtașli M, Can H, Türköz E, Can M. Fluoride release from various restorative materials. J Nihon Univ Sch Dent 1997;39:123-127.

5. Pereira LC, Nunes MC, Dibb RG, Powers JM, Roulet JF, Navarro MF. Mechanical properties and bond strength of glass-ionomer cements. J Adhesive Dent 2002;4:73-80.

6. Hickel RA, Folwaczny M. Various forms of glass ionomers and compomers. Oper Dent 2001;Supplement (6):177-190.

7. Di Lenarda R, Cadenaro M, De Stefano DE. Cervical compomer restorations: The role of cavity etching in a 48-month clinical evaluation. Oper Dent 2000;25:382-387

8. Palma-Dibb RG, Palma AE, Matson E, Chinelatti MA, Ramos RP. Microhardness of esthetic restorative materials at different depths. Mater Res 2002;6:85-90.

9. Williams JA, Billington RW, Pearson GJ. The comparative strengths of commercial glass-ionomer cements with and without metal additions. Br Dent J 1992;172:279-282.

10. Fleming GJ, Burke FJ, Watson DJ, Owen FJ. Materials for restoration of primary teeth: I. Conventional materials and early glass ionomers. Dent Update 2001;28:486-491.
11. Berg JH. The continuum of restorative materials in pediatric dentistry - a review for the clinician. Pediat Dent 1998;20:93-100

12. Gladys S, Van Meerbeek B, Braem M, Lambrechts P, Vanherle G. Comparative pysico-mechanical characterization of new hybrid restorative materials with conventional glass-ionomer and resin composite restorative materials. J Dent Res 1997;76:883-894.

13. Bollen CM, Papaioanno W, Van Eldere J, Schepers E, Quirynen $M$, van Steenberghe $D$. The influence of abutment surface roughness on plaque accumulation and peri-implant mucositis. Clin Oral Implants Res 1996;7:201-211.

14. Weitman RT, Eames WB. Plaque accumulation on composite surfaces after various finishing procedures. JADA 1975;91:101-106.

15. Shintani H, Satou J, Satou N, Hayashihara H, Inoue T. Effects of various finishing on staining and accumulation of Streptococcus mutans HS-6 on composite resins. Dent Mater 1985;1:225-227.

16. Pedrini D, Candido MSM, Rodrigues AL. Analysis of surface roughness of glass-ionomer cements and compomer. $J$ Oral Rehabil 2003;30:714-719.

17. Bagheri R, Burrow MF. Tyas MJ. Surface characteristics of aesthetic restorative materials - an SEM study. J Oral Rehabil 2007;34:68-76.

18. Yap AUJ, Sau CW, Lye KW. Effects of finishing time on surface characteristics of tooth-coloured restoratives. J Oral Rehabil 1998;25:456-461.

19. Tate WH, Powers JM. Surface roughness of composites and hybrid ionomers. Oper Dent 1996;21:53-58.

20. Ozgunaltay G, Yazıcı AR, Gorucu J. Effect of finishing and polishing and polishing procedures on the surface roughness of new tooth-colored restoratives. J Oral Rehabil 2003;30:218-224.

21. Wilder AD Jr, Swift EJ Jr, May KN Jr, Thompson JY, McDougal RA. Effect of finishing technique on the microleakage and surface texture of resin-modified glass ionomer restorative materials. J Dent 2000;28:367-373.

22. Reis AF, Giannini M, Lovadino JR, Ambrosano GM. Effects of various finishing systems on the surface roughness and staining susceptibility of packable composite resins. Dent Mater 2003;19:12-18.

23. Pitkethy M. Nanoparticles as building blocks. Materials Today 2003;6:36-42.

24. Yap, S, Yap A. Polish retention of new aesthetic restorative materials over time. Singapore Dental J 2004;26:39-43.

25. Tjan AH, Morgan DL. Metal reinforced glass ionomers: their flexural and bond strengths to tooth substrate. J Prosthet Dent 1988;59:137-141. 
26. Beyls HMF, Verbeek RMH, Marten LC, Lemaitre L. Compressive strength of some polyalkenoates with or without dental amalgam alloy incorporation. Dent Mater 1991;7:151154.

27. Kerby RE, Bleiholder RF. Physical properties of stainlesssteel and silver-reinforced glass ionomer cements. J Dent Res 1991;70:1358-1361.

28. Williams JA, Billington RW. Changes in compressive strength of glass ionomer materials with respect to time periods of $24 \mathrm{~h}$ to 4 months. J Oral Rehabil 1991;18:163-168.

29. Sarkar NK. Metal-matrix interface in reinforced glass ionomers. Dent Mater 1999;15:421-425.

30. Yap AUJ, Teo JCM, Teoh SH. Comparative wear resistance of reinforced glass ionomer restorative materials. Oper Dent 2000;26:343-348.

31. Xie D, Brantley WA, Culbertson BM, Wang G. Mechanical properties and microstructures of glass-ionomer cements. Dent Mater 2000;16:129-138.

32. Roulet JF, Walti C. Influence of oral fluid on composite resin and glass-ionomer cement. J Prosthet Dent 1984;52:182189.

33. Turssi CP, Hara AT, Serra MC, Rodrigues AL. Effect of storage media upon the surface micromorphology of resinbased restorative materials. J Oral Rehabil 2002;29:864871.

34. Nagaraja UP, Kishore G. Glass ionomer cement - the different generations. Trends Biomaterial Artif Organs 2005;18:158-165.

35. Aliping-McKenzie M, Linden RW, Nicholson JW. The effect of saliva on surface hardness and water sorption of glass-ionomers and "compomers". J Mater Sci Mater Med 2003;14:869-873.

36. Ellakuria J, Triana R, Mínguez N, Soler I, Ibaseta G, Maza J, García-Godoy F. Effect of one-year water storage on the surface microhardness of resin-modified versus conventional glass-ionomer cements. Dent Mater 2003;19:286290. 